\title{
Does the casting mode influence microstructure, fracture and properties of different metal ceramic alloys?
}

\begin{abstract}
José Roberto de Oliveira Bauer(a) Rosa Helena Miranda Grande ${ }^{(b)}$ Leonardo Eloy Rodrigues-Filho(b) Marcelo Mendes Pinto(c) Alessandro Dourado Loguercio(d)
\end{abstract}

(a) Department of Dentistry I, Federal University of Maranhão - UFMA, São Luís, MA, Brazil.

(b) Department of Dental Materials, University of São Paulo, São Paulo, SP, Brazil.

(c) Department of Dental Materials, University Nove de Julho, São Paulo, SP, Brazil.

(d) Department of Restorative Dentistry, State University of Ponta Grossa, Ponta Grossa, PR, Brazil.
Declaration of Interests: The authors certify that they have no commercial or associative interest that represents a conflict of interest in connection with the manuscript.

\section{Corresponding Author:}

José Roberto Oliveira Baver

E-mail: baver@ufma.br

Received for publication on Oct 18, 2011 Accepted for publication on Feb 28, 2012

\begin{abstract}
The aim of the present study was to evaluate the tensile strength, elongation, microhardness, microstructure and fracture pattern of various metal ceramic alloys cast under different casting conditions. Two Ni-Cr alloys, Co-Cr and $\mathrm{Pd}-\mathrm{Ag}$ were used. The casting conditions were as follows: electromagnetic induction under argon atmosphere, vacuum, using blowtorch without atmosphere control. For each condition, 16 specimens, each measuring $25 \mathrm{~mm}$ long and $2.5 \mathrm{~mm}$ in diameter, were obtained. Ultimate tensile strength (UTS) and elongation (EL) tests were performed using a Kratos machine. Vickers Microhardness (VM), fracture mode and microstructure were analyzed by SEM. UTS, EL and VM data were statistically analyzed using ANOVA. For UTS, alloy composition had a direct influence on casting condition of alloys (Wiron 99 and Remanium CD), with higher values shown when cast with Flame/Air $(\mathrm{p}<0.05)$. The factors "alloy" and "casting condition" influenced the EL and VM results, generally presenting opposite results, i.e., alloy with high elongation value had lower hardness (Wiron 99), and casting condition with the lowest EL values had the highest VM values (blowtorch). Both factors had significant influence on the properties evaluated, and prosthetic laboratories should select the appropriate casting method for each alloy composition to obtain the desired property.
\end{abstract}

Descriptors: Dental Casting Techniques; Dental Alloys; Hardness Test; Tensile Strength; Metal Ceramic Alloys.

\section{Introduction}

Among the innumerable advantages of $\mathrm{Ni}-\mathrm{Cr}$ and $\mathrm{Co}-\mathrm{Cr}$ alloys, the most outstanding are their low cost, ${ }^{1,2}$ high modulus of elasticity ${ }^{3}$ and being relatively easy to cast, using a blowtorch as a heat source., ${ }^{4,5}$

However, some studies have demonstrated that when noble ${ }^{6}$ and basic alloys $^{7}$ are cast in an uncontrolled environment, the metals are exposed to deleterious gases and elements, such as nitrogen and oxygen which they may absorb from the atmospheric air. This gas absorption, which is extremely dependent on the heating time, alloy composition and casting methods, ${ }^{8}$ may negatively influence their resistance to corrosion or mechanical properties, because it induces internal porosity. It is known that the casting process may increase the porosity of noble alloys, particularly those containing palladium $(\mathrm{Pd})$ in their composition. ${ }^{9}$

Another source of alloy contamination during the casting process is 
the combustion gas used in the blowtorch, which leads to carbon formation. ${ }^{10}$ As fuel for a (gas/ oxygen) blowtorch, hydrogen derived from the decomposition of $\mathrm{H}_{2} \mathrm{O}$ may be used, since this gas has great affinity for Pd.

The process of casting these alloys may be improved with the use of casting machines requiring different heat sources, which have been developed for titanium alloy casting. ${ }^{11}$ Machines that associate a controlled environment with inert gas as a heat source may be able to reduce the contamination of alloy. ${ }^{12}$ In addition, they allow the temperature to be controlled, with the technical advantage of reducing heating time and eliminating the need for flame adjustment. Moreover, there is reduced contamination, less probability of burning the metal, and consequently, less porosity due to volatilization of components with low melting temperatures. ${ }^{13}$

However, the mechanical properties and microstructure of different alloys indicated for Ni-Cr, Co$\mathrm{Cr}$ and Pd-Ag metal ceramics cast under different casting conditions are not known, and the object of this study was to investigate these factors.

\section{Methodology}

Two Ni-Cr-based alloys (Wiron 99, Bego, Bremen, Germany; and Suprem Cast V, Talladium Inc, Valencia, USA), one Co-Cr-based alloy (Remanium $\mathrm{CD}$, Dentaurum, Pforzheim, Germany) and one Pd-Ag-based alloy (W-1, Ivoclar Vivadent, Schaan, Liechtenstein) were evaluated. The composition of the alloys is presented in Table 1.

Test specimens (cps) were obtained by means of wax patterns measuring $25 \mathrm{~mm}$ long and $2.5 \mathrm{~mm}$ in diameter $(\mathrm{n}=16)$. The wax patterns were included in a phosphated lining (Micro-fine 1700, Talladium Inc, Valencia, USA) immediately after fabrication, using a metal mold. After final setting of the lining, each ring was put into a furnace (Ovmat-7, F.lli Manfredi, Torino, Italy).

After this, each of the alloys was cast according to the casting conditions to be tested:

1. (Flame/Air) gas/oxygen blow torch (Kerr Manufacturing Co, Orange, USA);

2. (Induction/Argon) electromagnetic induction (Easyti System, F.lli Manfredi, Torino, Italy), in an environment controlled with argon (Air Liquide, Sao Paulo, Brazil);

3. (Induction/Vacuum) electromagnetic induction under vacuum;

4. (Induction/Air) electromagnetic induction without control of the environment.

Each sample was tested under tension at a crosshead speed of $1 \mathrm{~mm} / \mathrm{min}$ in a testing machine ( $\mathrm{Kra}$ tos, Sao Paulo, Brazil). Ultimate tensile strength and elongation to failure were determined. In addition, two of the fractured tensile specimens from each group were investigated by scanning electron microscopy (SEM) (JEOL JSM 6300, Tokyo, Japan) to characterize their fracture mode. The fracture mode results were evaluated only qualitatively.

After the tensile test, one half of two different fractured specimens were embedded in bakelite for metallographic sample preparation. The prepared surfaces were examined under a stereomicroscope (100×, Shimadzu HMV-2, Tokyo, Japan).

Microhardness was measured using a Vickers indenter (Shimadzu HMV-2, Tokyo, Japan) with a $1000 \mathrm{~g}$ load and a loading time of $10 \mathrm{~s}$. Four measurements were made in each cast specimen.

\section{Statistical analysis}

The tensile strength $(\mathrm{MPa})$, elongation $(\%)$ and

Table 1 - Composition of alloys used in this study ( $w+\%)$.

\begin{tabular}{|c|c|c|c|c|c|c|c|c|c|c|c|c|c|}
\hline Alloys & $\mathrm{Ni}$ & Co & $\mathrm{Cr}$ & $\mathrm{Nb}$ & Mo & $\mathrm{Be}$ & Si & $\mathrm{Al}$ & $\mathrm{Sn}$ & $\mathrm{Ti}$ & $\mathrm{Ag}$ & $\mathrm{Pd}$ & Others \\
\hline Wiron 99 & 65.0 & - & 22.5 & 1.0 & 9.5 & - & 1.0 & 2.2 & - & 0.4 & - & - & \\
\hline Suprem Cast V & 74.0 & - & 14.0 & - & 8.5 & 1.8 & - & 1.7 & - & - & - & - & \\
\hline Remanium CD & - & 65.0 & 28.0 & & 4.5 & & 1.6 & & - & - & - & - & $\mathrm{Fe}, \mathrm{Mn}, \mathrm{Al}, \mathrm{La}, \mathrm{Ce}$ \\
\hline W-1 & - & - & - & - & - & - & - & - & 8.5 & - & 37.7 & 53.3 & In, Ru, Li \\
\hline
\end{tabular}


Vickers microhardness (VHN) data were subjected to a two-way ANOVA (Alloy versus Casting condition) and Tukey's test for pair-wise comparisons (0.05). The microstructure and fracture pattern results were evaluated only qualitatively.

\section{Results}

\section{Tensile strength}

Two-way ANOVA detected interaction between alloy and casting condition $(\mathrm{p}<0.05$, Table 2$)$. For the Suprem Cast V and W-1 alloys the different casting procedures did not influence the tensile strength means. Suprem Cast V alloy showed the highest tensile strength means under all conditions $(\mathrm{p}<0.05)$, whereas the lowest tensile strength means were observed for the Wiron 99 and Remanium CD alloys when cast under the induction/argon and induction/ vacuum condition respectively.

\section{Elongation}

Only the main factors were statistically significant $(\mathrm{p}<0.05$, Table 3$)$. With regard to the factor "alloy", the following materials were ranked in as- cending order: W-1 < Suprem Cast V $<$ Remanium $\mathrm{CD}<$ Wiron 99. As regards the casting condition, the lowest elongation values were found for Flame/ Air, with the highest values being obtained when casting was performed with Induction/Vacuum and Induction/Argon $(\mathrm{p}<0.05)$.

\section{Vickers microhardness}

Only the main factors were significant $(\mathrm{p}<0.05$, Table 4). For the factor alloy, there were significant differences for all the materials, in the following decreasing order of values: Suprem Cast V > Remanium CD > W-1 > Wiron 99. In the case of heat sources, the lowest microhardness values were found for Induction/Argon casting and the highest for Flame/ Air casting $(\mathrm{p}<0.05)$.

\section{Microstructure}

Figures 1, 2, 3 and 4 show the microstructure of the different alloys. No obvious microstructural differences were observed for the same alloy under the different casting conditions. Differences were only noted when different alloys were compared. All

Table 2 - Means and standard deviations of ultimate tensile strength (MPa).

\begin{tabular}{c|c|c|c|c}
\hline \multirow{2}{*}{} & \multicolumn{4}{|c}{ Ultimate tensile strength } \\
\cline { 2 - 5 } & Flame/Air & Induction/Air & Induction/Vacuum & Induction/Argon \\
\hline Suprem Cast V & $1024 \pm 58^{\mathrm{a}}$ & $1030 \pm 54^{\mathrm{a}}$ & $1027 \pm 65^{\mathrm{a}}$ & $1026 \pm 74^{\mathrm{a}}$ \\
\hline Wiron 99 & $650 \pm 64^{\mathrm{d}}$ & $623 \pm 49^{\mathrm{d}, \mathrm{e}}$ & $576 \pm 34^{\mathrm{e}}$ & $572 \pm 29^{\mathrm{e}}$ \\
\hline Remanium CD & $864 \pm 44^{\mathrm{b}}$ & $741 \pm 55^{\mathrm{c}}$ & $659 \pm 58^{\mathrm{d}}$ & $665 \pm 43^{\mathrm{d}}$ \\
\hline W-1 & $622 \pm 25^{\mathrm{d}, \mathrm{e}}$ & $625 \pm 48^{\mathrm{d}, \mathrm{e}}$ & $618 \pm 73^{\mathrm{d}, \mathrm{e}}$ & $608 \pm 51^{\mathrm{d}, \mathrm{e}}$ \\
\hline
\end{tabular}

Different letters indicate statistically significant differences (Tukey, $\mathrm{p}<0.05$ ).

Table 3 - Means and standard deviations of elongation (\%).

\begin{tabular}{|c|c|c|c|c|c|}
\hline \multirow{3}{*}{ Alloys } & \multicolumn{4}{|c|}{ Elongation } & \multirow{3}{*}{$\begin{array}{c}\text { Total mean } \\
\text { of alloys }\end{array}$} \\
\hline & \multicolumn{4}{|c|}{ Casting methods } & \\
\hline & Flame/Air & Induction/Air & Induction/Vacuum & Induction/Argon & \\
\hline Suprem Cast V & $7.25 \pm 2.2$ & $8.20 \pm 3.0$ & $9.44 \pm 2.9$ & $10.3 \pm 2.1$ & $8.80 \pm 2.6^{c}$ \\
\hline Wiron 99 & $46.2 \pm 9.2$ & $49.9 \pm 8.1$ & $51.3 \pm 8.1$ & $50.4 \pm 5.4$ & $49.5 \pm 7.7^{\mathrm{A}}$ \\
\hline Remanium CD & $12.1 \pm 1.7$ & $13.4 \pm 1.9$ & $12.9 \pm 1.9$ & $14.4 \pm 2.9$ & $13.2 \pm 2.1^{\mathrm{B}}$ \\
\hline W-1 & $4.89 \pm 1.1$ & $4.89 \pm 2.0$ & $6.90 \pm 1.5$ & $7.33 \pm 1.3$ & $6.00 \pm 1.5^{\mathrm{D}}$ \\
\hline Total mean of casting methods & $19.1 \pm 3.8^{b}$ & $20.1 \pm 3.6^{a}$ & $20.6 \pm 2.9^{\circ}$ & $20.6 \pm 2.9^{a}$ & \\
\hline
\end{tabular}

Different superscript lower case letters indicate statistical significance for the factor "casting methods", and different superscript capital letters indicate statistical significance for the factor "alloy" (Tukey, $\mathrm{p}<0.05$ ). 
Table 4 - Means and standard deviations of Vickers Hardness.

\begin{tabular}{|c|c|c|c|c|c|}
\hline \multirow{3}{*}{ Alloys } & \multicolumn{4}{|c|}{ Microhardness } & \multirow{3}{*}{ Total mean of alloys } \\
\hline & \multicolumn{4}{|c|}{ Casting methods } & \\
\hline & Flame/Air & Induction/Air & Induction/Vacuum & Induction/Argon & \\
\hline Suprem Cast V & $353 \pm 17.1$ & $371 \pm 4.2$ & $362 \pm 9.6$ & $352 \pm 4.3$ & $360 \pm 8.8^{A}$ \\
\hline Wiron 99 & $208 \pm 5.0$ & $209 \pm 5.8$ & $202 \pm 15.3$ & $194 \pm 4.2$ & $203 \pm 7.6^{D}$ \\
\hline Remanium CD & $361 \pm 13.7$ & $337 \pm 18.4$ & $340 \pm 3.9$ & $340 \pm 13.7$ & $345 \pm 11.7^{B}$ \\
\hline W-1 & $242 \pm 45.8$ & $238 \pm 4.4$ & $238 \pm 5.8$ & $224 \pm 13.8$ & $236 \pm 17.5^{c}$ \\
\hline Total mean of Casting methods & $291 \pm 20.4^{a}$ & $289 \pm 8.2^{a}$ & $286 \pm 8.7^{a, b}$ & $278 \pm 9.0^{b}$ & \\
\hline
\end{tabular}

Different superscript lower case letters indicate statistical significance for the factor "casting methods", and different superscript capital letters indicate statistical significance for the factor "alloy" (Tukey, $\mathrm{p}<0.05)$.

alloys exhibited a solid solution matrix in a typical dendritic arrangement. The Suprem Cast (Ni-Cr-Be) microstructure (Figure 1) shows evidence of a dendritic microstructure and an interdendritic portion with lamellar eutectic structures, possibly Ni-Be. In Figure 2 [Wiron 99 (Ni-Cr)], a high volume of solid solution with few areas of interdendritic structures is observed. This is probably due to the high solubility of the alloying elements ( $\mathrm{Cr}, \mathrm{Mo}$ and $\mathrm{Nb}$ ) in the Ni-matrix. The W-1 microstructure (Pd-Ag) presents white plates that represent the dendritic region, and black plates, possibly a large volume of segregated portion (Figure 3). Figure 4 shows the Remanium CD microstructure (Co-Cr). This alloy is characterized by a high volume of solid solution and low content of interdendritic portion and precipitates.

\section{Fracture mode (SEM)}

The different casting conditions did not influence the fracture mode of the alloys. Suprem Cast V alloy showed a friable type of fracture due to the absence of cracks on the external surface of the test specimen. There was presence of globules in the inner portion of this alloy, showing evidence of absence of flow in the fracture region.

The Wiron 99 alloy test specimen showed a large external deformation, which resulted in loss of its circular shape. Its internal portion was marked by deformation or flow of dendrites.

The W-1 alloy test specimen showed a friable type of fracture due to absence of cracks on the external surface of the specimen. Its internal por- tion was characterized by the formation of dimples, which demonstrated low elongation. Remanium CD alloy was characterized by the scarce presence of cracks indicating some deformation before rupture. Its internal portion was marked by the formation of laminas of rupture, which was characteristic of low elongation.

\section{Discussion}

The microstructure of $\mathrm{Ni}-\mathrm{Cr}$-Be alloys shows a large volume fraction of Ni-Be in solid solution (Figure 1), as secondary phase located in the interdendritic portion, which promotes an increase in tensile strength and microhardness. ${ }^{10}$ This can be observed when compared with other alloys without Be, such as Wiron 99, which showed complete absence of an interdendritic region (Figure 2).

Explanations for the high tensile strength, microhardness and low elongation values perhaps reside in the interdendritic portion and presence of $\mathrm{Be}$, an element that is a grain refiner and hardener of $\mathrm{Ni}$ Cr alloys. ${ }^{14}$ Moreover, there is the presence of other elements, such as $\mathrm{C}$ and Al. Aluminum provides an increase in mechanical properties in $\mathrm{Ni}-\mathrm{Cr}$ alloys by forming a hardening compound $\left(\mathrm{Ni}_{3} \mathrm{Al}\right)$, and $\mathrm{C}$ in concentrations from $1 \%$ to $3 \%$ significantly increases the hardness values and diminishes elongation. ${ }^{15}$

Wiron-99 alloy showed low tensile strength and microhardness values, but higher elongation values. These values can be explained when one observes the composition of this alloy, which contains elements with high solubility, such as $\mathrm{Cr}$, Mo and $\mathrm{Nb},{ }^{10}$ in the Ni matrix. Thus, hardness and tensile 


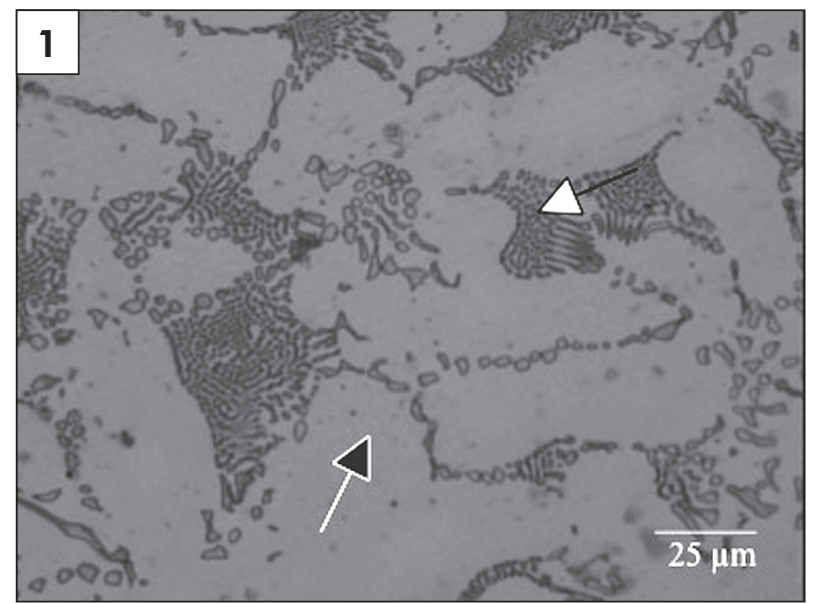

Figure 1 - The Suprem Cast V microstructure showed the presence of a dendritic (white arrow) and an interdendritic portion with lamellar eutectic structures (black arrow), possibly $\mathrm{Ni}-\mathrm{Be}$.

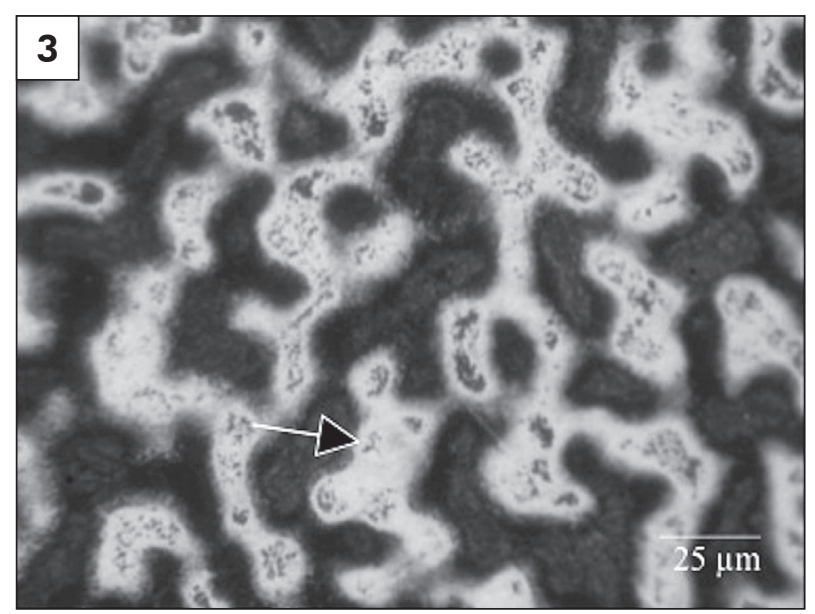

Figure 3 - W-1 presented white plates that represent the dendritic region (black arrow) and black plates, possibly a large volume of segregated portion.

strength are increased with the inclusion of elements such as $\mathrm{Si}, \mathrm{C}$ and $\mathrm{Fe}$, which act as precipitates within the Ni matrix. ${ }^{16}$ This is confirmed with the observation of a large volume of solid solution and absence of the interdendritic portion in the microstructure (Figure 2). Nevertheless, the Ni-Cr alloys may cause a hypersensitivity reaction to $\mathrm{Ni}^{17}$

The Pd-Ag alloy (W-1) has a high modulus of elasticity, obtains excellent bond to porcelain, is high temperature resistant (sag), easy to use and resistant to corrosion. ${ }^{18}$

Among all the alloys, W-1 was the one that

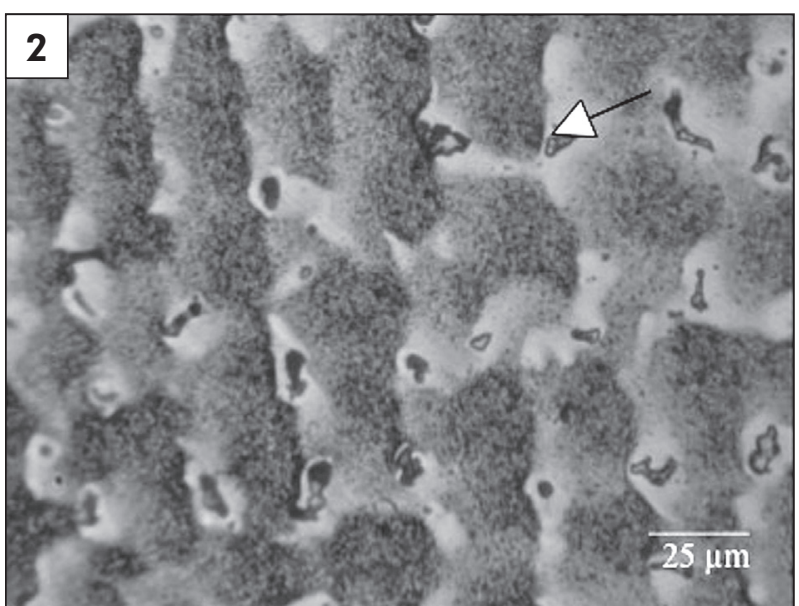

Figure 2 - Wiron 99 showed high volume of solid solution with few areas of interdendritic structures. Note the presence of precipitates (white arrow).

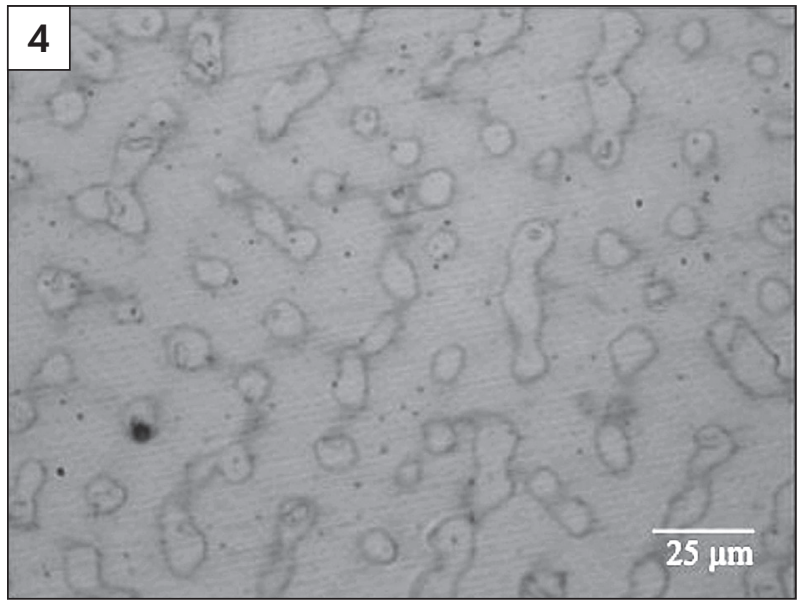

Figure 4 - Remanium CD alloy showed a microstructure characterized by a high volume of solid solution

demonstrated the least elongation. This may be explained by the remarkable presence of $\mathrm{C}$, an interstitial element that inhibits flow and deformation of the crystalline grid or the presence of grain refining elements, in this case Rutile. ${ }^{19}$ A possible reason for the low elongation and high hardness of this alloy lies in the formation of a dendritic microstructure that has an interdendritic portion with a large volume, which makes stress propagation difficult. ${ }^{20}$ The presence of a dendritic microstructure is of great importance in mechanical properties, ${ }^{21}$ confirmed by the observation of the fracture pattern of 
this alloy, which presented no crack formation on the external surface of the test specimen. Therefore, Co-Cr alloys have been proposed as an excellent alternative to high cost noble alloys and the biologic problems related to $\mathrm{Ni}-\mathrm{Cr}$ alloys. $\mathrm{Co}-\mathrm{Cr}$ alloys have good mechanical properties, such as microhardness and tensile strength, obtained due to the combination of a solid solution hardener and $\mathrm{C}, \mathrm{Cr}, \mathrm{Mb}$ and $\mathrm{W}$ precipitates in the pure Co matrix. ${ }^{22}$ The elongation results obtained were shown to be superior to those of Suprem Cast V and W-1 alloys, completely compatible with the fracture pattern, which showed deformation of the dendrites and crack formation before rupture. The flame/air process significantly affected the tensile strength of Wiron 99 and Remanium CD alloys, which showed a trend towards elevation of values. Flame/air also presented the lowest elongation values, and highest Vickers microhardness values. This could be attributed to the incorporation of contaminants such as $\mathrm{C}$, an interstitial element, arising from the combustion of gases arising from the heat source. ${ }^{10}$ Casting by flame/air, combined with alloys that present elements such as $\mathrm{Cr}$, $\mathrm{Ti}, \mathrm{Nb}, \mathrm{Si}$ and $\mathrm{Mb}$ in their composition, may lead to the formation of carbides of the $\mathrm{MC}, \mathrm{M}_{6} \mathrm{C}, \mathrm{M}_{7} \mathrm{C}_{3}$, $\mathrm{M}_{23} \mathrm{C}_{6}$ and $\mathrm{M}_{2} \mathrm{C}_{3}$ type. $^{23}$

Furthermore, an increase in the concentration of C may increase the Vickers microhardness, tensile strength and diminish elongation, as the carbides are hard and friable. This results in the initiation of cracks within the carbide thus leading to a reduction in ductility. ${ }^{24}$ Therefore, the hypothesis is that the high concentration of $\mathrm{Cr}$ in these alloys may have been a crucial factor in the sensitivity to the casting process. Therefore, basic alloys with low $\mathrm{Cr}$ content tend to behave indifferently, irrespective of how they are cast, in this case the Suprem Cast V alloy.

Alloys that contain Pd are known for their capacity to absorb gases from the environment during the casting process, particularly when heated with an inadequately set blowtorch. ${ }^{9}$ Perhaps this capacity of Pd alloy to absorb gases did not have such a pronounced effect on the mechanical properties in this study. An advantage of controlling the casting temperature is that it prevents the materials from being overheated, and consequently, precludes the creation of porosities by volatilization of components with lower fusion temperatures.

From a clinical point of view, the casting method can influence the surface roughness of the part due to oxidation of the metal casting under different conditions. This can lead to pathogenic microorganisms becoming attached to rough alloy surfaces, resulting in increased incidence of oral diseases ${ }^{25,26}$ and acceleration of biocorrosion due to providing retentive niches. ${ }^{27}$ Moreover, alloy casting done in a protected environment significantly decreased roughness and provided samples with smoother surfaces when compared with acetylene-oxygen flame casting. This is very important because the smoother surfaces facilitate finishing and polishing procedures, especially in areas of difficult access. Greater surface roughness requires additional finishing and polishing procedures, increasing the time necessary to complete these procedures. ${ }^{13}$

\section{Conclusion}

The casting method without control of the environment, mainly using a blowtorch, tended to increase the microhardness and decrease the elongation of the alloys. With regard to alloys, Ni-CrMo alloys showed the highest EL and lowest VM. Ag-Pd alloy had the worst elongation and $\mathrm{Ni}-\mathrm{Cr}-\mathrm{Be}$ the highest VM values. Regarding tensile strength, $\mathrm{Ni}-\mathrm{Cr}-\mathrm{Be}$ (highest UTS) and Ag-Pd (lowest UTS) alloys were not influenced by the casting methods, however, Ni-Cr-Mo and Co-Cr were significantly improved by using the blowtorch.

The composition of the alloys, as well as the casting methods significantly influenced the properties evaluated. Prosthetic laboratories should select the appropriate casting method for each alloy composition in order to obtain the desired property.

\section{Acknowledgments}

This study was supported by the CNPq (grant no. 479369/2009-7) and FAPEMA (grants no. 01164/09 and no. 617/2011). 


\section{References}

1. Wataha JC. Biocompatibility of dental casting alloys: a review. J Prosthet Dent. 2000 Feb;83(2):223-34.

2. Dharmar S, Rathnasamy RJ, Swaminathan TN. Radiographic and metallographic evaluation of porosity defects and grain structure of cast chromium cobalt removable partial dentures. J Prosthet Dent. 1993 Apr;69(4):369-73.

3. Alada A, Comleko ME, Dundar M, Gungor MA, Artunc C. Effects of soldering and laser welding on bond strength of ceramic to metal. J Prosthet Dent. 2011 Jan;105(1):28-34.

4. Bauer JRO, Loguercio AD, Reis A, Rodrigues Filho LE. Microhardness of $\mathrm{Ni}-\mathrm{Cr}$ alloys under different casting conditions. Braz Oral Res. 2006 Jan-Mar;20(1):40-6.

5. Bezzon OL, de Mattos MGC, Ribeiro RF, Rollo JM. Effect of beryllium on the castability and resistance of cerometal bonds in nickel-chromium alloys. J Prosthet Dent. 1998 Nov;80(5):570-4.

6. Engstrom G, Fredriksson H, Wictorin L. Absorption of gas in dental gold alloys during melting. J Oral Rehabil. 1982 Jan;9(1):35-44.

7. Strandman E. Influence of different types of acetylene-oxygen flames on the carbon content of a dental Co-Cr alloy. Odontol Revy. 1976;27(3):223-38.

8. Tajima K, Kakigawa H, Kozono Y, Hayashi I. Oxygen and nitrogen uptake in dental $\mathrm{Ni}-\mathrm{Cr}$ alloy castings by several melting methods. Dent Mater J. 1984 Dec;3(2):262-71.

9. Li D, Baba N, Brantley WA, Alapati SB, Heshmati RH, Daehn GS. Study of Pd-Ag dental alloys: examination of effect of casting porosity on fatigue behavior and microstructural analysis. J Mater Sci Mater Med. 2010 Oct;21(10):2723-31.

10. Baran GR. The metallurgy of Ni-Cr alloys for fixed prosthodontics. J Prosthet Dent. 1983 Nov;50(5):639-50.

11. Rodrigues RC, Faria AC, Orsi IA, Mattos M da G, Macedo AP, Ribeiro RF. Comparative study of two commercially pure titanium casting methods. J Appl Oral Sci. 2010 SepOct;18(5):487-92.

12. Bauer J, Cella S, Pinto MM, Rodrigues Filho LE, Reis A, Loguercio AD. Effect of argon purity on mechanical properties, microstructure and fracture mode of commercially pure (cp) $\mathrm{Ti}$ and $\mathrm{Ti}-6 \mathrm{Al}-4 \mathrm{~V}$ alloys for ceramometal dental prostheses. Biomed Mater. 2009 Dec;4(6):065002.

13. Bezzon OL, Pedrazzi H, Zaniquelli O, Silva TB. Effect of casting technique on surface roughness and consequent mass loss after polishing of $\mathrm{NiCr}$ and $\mathrm{CoCr}$ base metal alloys: a comparative study with titanium. J Prosthet Dent. 2004 Sep;92(3):274-7.
14. Eftekhari A. Fractal study of Ni-Cr-Mo alloy for dental applications: effect of beryllium. Appl Surf Sci. 2003 Dec;220(14):343-8.

15. Das S, Seol JB, Kim YC, Park CG. Structure and mechanical properties of $\mathrm{Ni}$-Cr alloy produced by single roll strip casting. Mater Des. 2010 Jan;31(1):570-3.

16. Bumgardner JD, Lucas LC. Surface analysis of nickel-chromium dental alloys. Dent Mater. 1993 Jul;9(4):252-9.

17. Gordon T, Bowser D. Beryllium: genotoxicity and carcinogenicity. Mutat Res. 2003 Dec;533(1-2):99-105.

18. Papazoglou E, Brantley WA, Johnston WA, Carr AB. Effects of dental laboratory processing variables and in vitro testing medium on the porcelain adherence of high-palladium casting alloy. J Prosthet Dent. 1998 May;79(5):514-9.

19. Brantley WA, Cai Z, Carr AB, Mitchell JC. Metallurgical structures of as-cast and heat-treated high-palladium dental alloys. Cells Mater. 1993;3(1):103-14.

20. Li D, Brantley WA, Guo W, Clark WA, Alapati SB, Heshmati $\mathrm{RH}$, et al. Fatigue limits and SEM/TEM observations of fracture characteristics for three Pd-Ag dental casting alloys. J Mater Sci Mater Med. 2007 Jan;18(1):119-25.

21. Papazoglou E, Wu Q, Brantley WA, Mitchell JC, Meyrick G. Comparison of mechanical properties for equiaxed finegrained and dendritic high-palladium alloys. J Mater Sci Mater Med. 2000 Oct;11(10):601-8.

22. Matkovic T, Matkovic P, Malina J. Effects of Ni and Mo on the microstructure and some other properties of $\mathrm{Co}-\mathrm{Cr}$ dental alloys. J Alloys Compd. 2004 Mar;366(1-2):293-7.

23. Piekarski B. Effect of $\mathrm{Nb}$ and $\mathrm{Ti}$ additions on microstructure, and identification of precipitates in stabilized $\mathrm{Ni}$-Cr cast austenitic steels. Materials Characterization 2001 Sep;47(34):181-6.

24. Ding R, Jones IP, Jiao H. Effect of carbon on the microstructures and mechanical properties of as cast $\mathrm{Nb}$-base alloy. Mater Sci Eng A Struct Mater. 2008 Jun;485(1-2):92-8.

25. Bollen CM, Lambrechts P, Quirynen M. Comparison of surface roughness of oral hard materials to the threshold surface roughness for bacterial plaque retention: a review of the literature. Dent Mater. 1997 Jul;13(4):258-69.

26. Sen D, Goller G, Issever $H$. The effect of two polishing pastes on the surface roughness of bis-acryl composite and methacrylate-based resins. J Prosthet Dent. 2002 Nov;88(5):527-32.

27. Mori T, Togaya T, Jean-Louis M, Yabugami M. Titanium for removable dentures. I. Laboratory procedures. J Oral Rehabil. 1997 May;24(5):338-41. 